DOI 10.37882/2223-2982.2021.09.02

\title{
ЛЕКСИКАЛИЗАЦИЯ АББРЕВИАТУР В ТЕХНИЧЕСКОМ ТЕКСТЕ
}

\section{LEXICALIZATION OF ABBREVIATIONS IN TECHNICAL TEXT}

I. Belikova

E. Kerber

Summary: The article deals with the process of lexicalization of terminological abbreviations, during which the initial abbreviation becomes a separate unit of language that corresponds to the language norm; units of secondary nomination, which acquire word status in English due to frequency of their usage, are analyzed. Particular attention is paid to the similarity of the abbreviation with the noun and the implementation of its grammatical properties. The theoretical aspect of the study presents the opinions of scientists concerning the stages of lexicalization, the status of the acronym and abbreviation in the language, and attention is also paid to the signs of content words, the functions of the lexical unit (linguistic sign). The study was conducted on the material of technical texts on thermal power engineering, electronics, neural networks and machine learning.

Keywords: abbreviation, lexicalization, acronym, linguistic sign, noun.

\author{
Беликова Ирина Александровна \\ К.филол.н., доцент, Омский Государственный \\ Технический Университет \\ irina.belikova@gmail.com \\ Кербер Елена Владимировна \\ К.филол.н., доцент, Омский Государственный \\ Технический Университет \\ Ikerber@mail.ru
}

Аннотация: В статье рассматривается процесс лексикализации терминологических сокращений, в ходе которого инициальное сокращение становится самостоятельной, полноправной единицей языка, отвечающей языковой норме; анализируются единицы вторичной номинации, приобретающие статус слова в английском языке в силу частотности их употребления. Особое внимание уделяется соответствию аббревиатуры с именем существительным и реализации его грамматических свойств. Теоретический аспект исследования затрагивает мнения ученых относительно этапов лексикализации, статуса акронима и аббревиатуры в языке, также уделяется внимание признакам знаменательных слов, функциям лексической единицы (языкового знака). Исследование проводилось на материале технических текстов по теплоэнергетике, электронике, нейросетям и машинному обучению.

Ключевые слова: аббревиатура, лексикализация, акроним, языковой знак, имя существительное.

Вслед за учеными А. Кеннеди, А.И. Смирницким, М.М.Сегаль, мы считаем, что вновь появившиеся аббревиатурные единицы не рассматриваются как слова, а превращаются в них в ходе языкового развития [цит. по Сергеева, 2013, 175]. Рассмотрим основные этапы лексикализации аббревиатуры, т.е. процесса, в результате которого сокращения приобретают признаки обычного слова.

Первый этап лексикализации характеризуется «побуквенной реализацией носителями языка большинства графических сокращений» [5, с.122], за которым следует процесс оптимизации фонетической структуры аббревиатуры. Признаком следующего этапа лексикализации Т.В. Максимова называет пропуск точек на письме, что приводит к постепенному переходу аббревиатур в разряд акронимов, фонетическая структура которых совпадает с фонетической структурой уже существующих в языке слов [4, с.178]. Далее частотное употребление иницианализма в разнообразных словосочетаниях приводит к тому, что данная языковая единица вступает в деривационные процессы и служит основанием для образования производных слов [6, с.89].

Слово традиционно признается основным и наиболее типичным языковым знаком, как и основной значимой единицей языка (А.И. Смирницкий, А.В. Кравченко). А.А. Уфимцева, объясняет это «семиологической ценно- 
стью»: слово обобщает (сигнификативная функция), даёт наименование, обозначает (номинативная функция), слово сообщает (выполняет коммуникативную функцию) и выражает определённое чувство, переживание говорящего, слушающего (прагматическая функция)» [цит. по Келлер, 2010, 88]. В данном случае был представлен практически весь объем языковых функций слова.

Обобщая вышесказанное, можно сказать, что языковой знак является по своей природе двусторонней психической сущностью, состоящий в единстве чувственно воспринимаемой, звуковой формы и значения, а именно понятия и акустического образа. Это суть билатеральной теории языкового знака, берущей начало в концепции Ф. де Соссюра. [7, с.87].

Итак, слово существует в звуковой и графической форме; слово именует предметы, процессы, свойства и отношения, заключая в себе присущее только ему лексическое значение; вступает в сочетания с другими словами, образуя словосочетания.

Как единица языка слово выступает в качестве грамматической единицы. Это проявляется в том, что каждое слово-лексема относится к определенному грамматическому разряду слов (существительные, глаголы, прилагательные, наречия, числительные и т.д.). Относясь к тому или иному грамматическому классу, слово обладает набором определенных грамматических категорий. Например, у существительных - это категории рода, числа, падежа. Набор грамматических форм определяется, в свою очередь, отнесенностью слова к определенной части речи.

Наконец, слово как языковая единица выступает в качестве «строительного» элемента синтаксиса, т.к. синтаксические единицы (словосочетание, предложение, текст) образованы из слов на основе того или иного варианта их комбинированного использования.

Таким образом, слово представляет собой целостную, фонетически и грамматически оформленную значимую единицу языка, которой свойственны относительная непроницаемость, лексико-грамматическая отнесенность и воспроизводимость в речи.

М.А. Ярмашевич говорит о том, что аббревиатурное образование обнаруживает все признаки, присущие знаменательным словам: признак номинативности и два типа структурных отношений - парадигматические (возможность выбора в процессе речи единицы, нужной в данном тексте) и синтагматические (синтаксическая и лексическая сочетаемость друг с другом) [цит. по Князев, $2014,88]$. Лексическая сочетаемость обусловливается: а) предметно-смысловыми связями, б) грамматическими свойствами; в) собственно лексическими особенностями.
При рассмотрении соотношения аббревиатур со структурой слов в прагматическом плане необходим комплексный подход, при котором объективно учитываются семантические, стилистические, структурные, грамматические и акцентологические особенности аббревиатур и слов. [5, с.122]

Семантическая составляющая аббревиатур определяется значением ее компонентов. Считается, что значение аббревиатур передается расшифровкой ее сокращенных элементов. Следствием лексикализации являются новые значения старых слов и их комбинаций, которые утрачивают свою содержательную и формальную членимость, начиная использоваться как цельнооформленные сло-ва (ср: (англ.) PR - public relations и (русс.) пиар, пиарщик). Таким образом, лексикализация обогащает словарь [2, с.42]. Но данное утверждение, на наш взгляд, в меньшей степени относится к терминологической сокращенной лексике, что вполне объяснимо, ведь она в силу устойчивости узкоспециального значения реже подвержена трансформации лексико-фразеологического характера.

Вступая в синтагматические отношения, в предложении алфабетизмы (инициальные сокращения) и их производные могут выполнять практически все синтаксические функции $[9,264]$. По наблюдениям М.А. Ярмашевич, акронимы и графо-лексические аббревиатуры практически всегда являются существительными и могут использоваться атрибутивно, как любое другое существительное, находящееся в препозиции по отношению к определяемому им слову [9, с.265]. Подавляющее большинство сокращений выступают в роли существительных, выражающих семантическую категорию предметности. В меньшей степени аббревиатурами могут быть глаголы и имена прилагательные, (то есть выражать, соответственно, семантические категории действия и признака) [5, с.123].

Как было сказано выше, аббревиатура, приобретая статус слова, может участвовать в дерривационных процессах. По мнению Н.Т. Николаевой от аббревиатур могут образовываться новые слова с помощью традиционных способов словообразования: а) словопроизводства; б) словосложения; в) конверсии [цит. по Вишнякова, 2014].

Для наименования отаббревиатурных образований используют следующие термины: «отаббревиатурные производные», «корневые аббревиатуры», и «аббревемы». Н.Н. Сафонова вводит еще одно понятие - «отаббревиаты». Целесообразность такого термина объясняется тем, что он однословен, понятен и по своей структуре встает в один ряд с такими привычными названиями, как «дериваты», «субстантиваты», «универбаты» [10]. 


\section{Материал и методы исследования}

Подводя итог вышесказанному, отметим, что сокращенные словосочетания становятся неотъемлемой частью словарного состава английского языка, активно подвергаясь процессу лексикализации и становясь полноправными единицами языка. Принимая это во внимание, была поставлена цель выявить признаки вхождения аббревиатуры в языковую систему и факторы, способствующие превращению ее в полноценный языковой знак (соответствие фонетической структуры фонетическим и орфоэпическим нормам языка, номинативная способность, вступление в формально-структурные и синтагматические отношения, возможность семантического развития, участие в деривационных процессах).

Исследование выполнялось на материале текстов по теплоэнергетике (thermal power) электронике (hard software), нейросетям (neural network), машинному обучению (machine learning), а также на выборке сокращений в области компьютерных стандартов и протоколов.

В рамках лингвистического подхода был использован метод сравнительно-сопоставительного анализа, структурные методы морфемного и словообразовательного анализа. Также был проведен семантический анализ, который помог выявить сопутствующее значение инициального сокращения.

\section{Результаты исследования}

Проведенное исследование показало, что терминыаббревиатуры и термины-акронимы соотносятся, главным образом, с именем существительным и реализуют его грамматические категории.

Из синтаксических признаков существительных наиболее характерным является способность существительных определяться артиклями и другими словами, функционально аналогичными артиклям (т. н. детерминативами), а также прилагательными и числительными. При этом для существительных характерно препозитивное положение определяющих слов. Артикль служит определителем существительного, передает значение определенности/неопределенности существительного. The SOM thus forms the required topographic map of the input patterns. Таким образом, самоорганизующаяся карта формирует требуемую топографическую карту входных шаблонов. Agbossou et al. designed a work unit made of PCM and a TEG. Агбосоу и др. создали рабочую модель устройства на основе фазоименяющего материала и термоэлектрического генератора.

Имя прилагательное в функции определения стоит перед существительным (в нашем случае перед акронимом), к которому оно относится. Build a simple SOM using MiniSom. Построй простую самоорганизующуюся карту, используя алгоритм MiniSom. It is important to say that the «traditional» S.M.A.R.T. did not predict failure for most of these hard disks. Важно сказать, что традиционная технология S.M.A.R.T не предсказала сбой для большинства этих жестких дисков. Figure 2 presents the average Annualized Failure Rates(AFR) for all drives in our study. На рис. 2 представлен усредненный годовой уровень ошибок для всех дисков, участвующих в нашем исследовании.

Исчисляемые аббревиатуры-существительные могут иметь форму единственного и множественного числа, что выражено как окончанием -s, так и указательным и личным местоимениями. Clearly our SOM must involve some kind of adaptive, or learning, process. Очевидно, что наша самооганизующаяся карта должна включать какойто адаптивный или обучающий процесс. This SOM has a feed-forward structure with a single computational layer arranged in rows and columns (перевод см выше). Then each of these $B M U s$ will be assigned a radius like in the image below. Тогда каждому из этих наиболее подходящих блоков будет назначен радиус, как представлено на картинке.

Подобно слову терминологические инициальные сокращения могут иметь падежные формы. Когда существительное является в предложении подлежащим или дополнением, оно стоит в общем падеже (the Common Case). Как и существительные, аббревиатуры в этом падеже своей грамматической формы не меняют. Как видно из примеров ниже, аббревиатура/акроним могут выполнять в предложении роль подлежащего и дополнения.

В качестве подлежащего инициальное сокращение выступает в следующих предложениях: As we will learn later, DMA is used in data copy operations between a CPU and a GPU. Как мы узнали ранее, прямой доступ к памяти используется в операциях копирования между чентральным процессором и графическим прочессором. It shows that when the PCM melts near the melting point, the temperature changes little up or down. Это показывает, что когда фазоизменяющий материал плавится вблизи точки плавления, температура изменяется в сторону небольшого повышения или понижения.

Исследование показало, что помимо традиционного для технических текстов времени группы Simple, аббревиатуры встречаются в предложениях группы Continuous и Perfect. S.M.A.R.T. is constantly analysing the disk surface during normal operations. Технология S.M.A.R.T. постоянно анализирует поверхность диска во время обычных операчий. Once the BMU has been determined, the next step is to calculate which of the other nodes are within the BMU's neighborhood. Когда наиболее подходящие блоки были определены, след шаг - рас- 
считать, какие из других узлов являются соседними с наиболее подходящими блоками. Аббревиатуры в роли подлежащего используются в вопросительных и отрицательных предложениях, согласуясь с соответствующим вспомогательным глаголом. How do CRCs work? Как работают чиклические избыточные коды? It is important to say that the «traditional» S.M.A.R.T. did not predict failure for most of these hard disks (превод см выше).

В качестве прямого дополнения инициальное сокращение выступает в следующих предложениях. Can we believe S.M.A.R.T.? Можем ли мы доверять технологии S.M.A.R.T.? The experimental results showed that the power conversion rate of the system can be increased by 35.3\% by using PCM. Экспериментальные результаты показали, что скорость преобразования мощности системы может быть увеличена на 35,3\% с помощью фазоизменяющего материала.

Намного больше примеров встречается с аббревиатурой в качестве косвенного предложного дополнения. Their results confirmed the potential of the application of PCM as a cooling/heating media in TEGs. Их результаты подтвердили потенциал применения фазоизменяющего материала в качестве охлаждающей/нагревающей среды в термоэлектрическом генераторе. They manufactured two aluminium boxes with different structures filled with РСМ. Они изготовили два алюминиевых ящика различной конструкции, заполненных фазоизменяющим материалом. The problems with S.M.A.R.T. C технологией S.M.A.R.T. существуют некоторые проблемы. With DIPM off, the recorded value will include all three device power states: active, idle and sleep. С выключенным управлением питания, записанное значение будет включать все три состояния питания устройства: активное, неактивное и спящее.

Притяжательный падеж (the Possessive Case) используется в основном для обозначения принадлежности к кому- или чему-либо. Образуется притяжательный падеж добавлением к основной форме существительного конструкции 's. Аналогичную конструкцию можно наблюдать и у терминов-аббревиатур. Множество примеров тому подтверждение. The SMSC advanced digital data separator incorporates SMSC's patented data separator technology, allowing for ease of testing and use. Улучшенный цифровой разделитель данных компании SMSC включает патентованную SMSC технологию разделения данных, позволяющую его легко тестировать и использовать. Once the BMU has been determined, the next step is to calculate which of the other nodes are within the BMU's neighborhood. Когда наиболее подходящие блоки были определены, след шаг - рассчитать, какие из других узлов являются соседними с наиболее подходящими блоками. The next step is to initialize the SOM's weights to small, standardized random values. Следующий шаг — это инициализировать веса самоорганизующейся карты в случайные, стандартизованные малые значения. It is necessary to look at S.M.A.R.T.'s roots, which are based in technology developed by IBM and Compaq. Необходимо посмотреть на истоки технологии S.M.A.R.T., которые основываются на технологиях, разработанных компаниями IBM и Compaq.

Помимо притяжательного падежа значение принадлежности может передаваться и существительным в общем падеже, употребляемым в функции определения (power supply - энергетическое nuтание). Инициальные сокращения зачастую также выступают в функции определяющего компонента словосочетания, как отмечает М. А. Ярмашевич, в силу «ускоренной динамики» и «высокой генеративная способности» моделей аббревиатурного словообразования [11, с.8,10]. Подобные теринообразования получили название «гибридных образований», под которыми И.А. Беликова понимает «многокомпонентные терминологические сочетания, где в качестве одного или нескольких компонентов выступают инициальные сокращения» [12, с.82]. Нами выделены следующие гибридные образования с аббревиатурой в функции препозитивного определения: TEG system, first TEG level radiator, PCM aluminium box, PCM container, TEG module, PCM effect, WSN application, WSN nodes, SOM algorithm и др.

Активное участие инициальных сокращений в дерривационных процессах подтверждают следующие гибриды, образованные морфологическим (аффиксация) и лексико-синтаксическим (словосложение) способами терминообразования. MiniSom can be installed using the Python package management utility pip. Пакет MiniSom может быть установлен, используя утилиту рір для управления Python-пакетами. For about a year I have been maintaining an open-source package called smartmontools, a spin-off of the UCSC smartsuite package, for this purpose. Около года я поддерживал пакет с открытыми исходными кодами, называемый «набор инструментов для работы со smart», который является продолжением пакета из UCSC, предназначенного для этой чели. The device uses a PCM-filled thermal storage unit. Устройство использует блок аккумулирования тепла, заполненный фазоизменяющим материалом. We apply the SOM-based botnet detection algorithm to the extracted graph-based features. Мы применяем алгоритм обнаружения ботнетов на основе самоорганизующейся карты к извлеченным функциям на основе графа. Depending on the type of interface being used, some S.M.A.R.T.-enabled motherboards and related software may not communicate with certain S.M.A.R.T.-capable drives. В зависимости om mипа используемого интерфейса некоторые системные платы с поддержкой S.M.A.R.T. и соответствующее программное обеспечение могут не взаимодействовать с определенными дисками, поддерживающими S.M.A.R.T. 
Проанализировав ряд предложений с акронимом S.M.A.R.T., нами был отмечен эмоционально-оценочный компонент, т.е. сопутствующее значение языковой единицы. В данном случае коннотацией, сопровождающей акроним S.M.A.R.T., можно считать: осмысленность, интеллектуальность, самостоятельность (в принятии решений). Данная коннотация присуща, как правило, одушевленному лицу, что делает эту технологию в каком-то смысле персонифицированной. S.M.A.R.T. in action. S.M.A.R.T. в действии. Также одушевленность подчеркивается грамматически временем группы Continuous активного залога: S.M.A.R.T. is constantly analysing the disk surface during normal operations. S.M.A.R.T. nocmoянно анализирует поверхность диска во время обычных операций. В ряде предложений коннотация усиливается семантикой сопровождающих глаголов predict (предсказывать) и believe (доверять), отражающих активного исполнителя действия, участника взаимоотношений. It is important to say that the S.M.A.R.T. did not predict failure for most of these hard disks. Важно сказать, что традиционная технология S.M.A.R.T. не предсказала сбой для большинства этих жестких дисков. Can we believe S.M.A.R.T.? Можем ли мы доверять S.M.A.R.T.?

В качестве особого случая можно назвать включение аббревиатуры в состав независимого причастного оборота, где роль существительного в общем падеже отводится инициальному сокращению. They are updated by the combine forces of these BMUs, with the nearest BMU being the most influential. Они обновляются совокупностью сил этих наиболее подходящий блоков, причем ближайший наиболее подходящий блок (BMU) будет испытывать наибольшее воздействие.

В заключении привожу примеры участия трех и более аббревиатур в рамках одного предложения для иллюстрации синтагматических отношений. The FDC will deactivate the IRQ pin and RQM bit when the FIFO becomes empty. Контроллер гибких дисков деактивирует вывод линии IRQ и бит RQM, когда очередь (буфер) становится nyсmoŭ. After all the result bytes have been read, the RQM and DIO bits switch to «1» and «0» respectively, and the $\mathrm{CB}$ bit is cleared, indicating that the FDC is ready to accept the next command. После прочтения всех байтов результата, биты RQM и DIO переключаются в «1»и «0» соответственно, и бит CВ очищается, означая что контроллер гибких дисков готов к принятию следующей команды. MPA includes an additional CRC check to increase data integrity when running over TСР. МРА-протокол включает дополнительную проверку контрольного кода для увеличения целостности данных, когда передается через протокол ТСР.

\section{Выводы}

Аббревиация остается в о многих отношениях загадкой в лингвистическом плане, так как применительно к ней рассматриваются под специфическим углом зрения такие фундаментальные проблемы, как проблема структуры слова и его значения, и проблема морфемы [13, с.173].

Исследование показало, что инициальные сокращения являются знаками переходного типа, т. е. конвенциональными знаками, вбирающими в себя все характеристики языковых знаков и обнаруживающими тенденции перехода в полнозначное слово. Исследование подтвердило, что произношение отдельных инициальных сокращений (акронимов) подчиняется фонетической организации полнозначных слов (SOM, TEG) и даже в ряде случаев приводит к омонимии акронима с обычным словом (S.M.A.R.T.).

Вступая в синтагматические отношения, в предложении алфабетизмы и их производные выполняют, в большинстве своем, функции подлежащего и дополнения, могут использоваться аттрибутивно в гибридных образованиях. Инициальные сокращения могут иметь форму единственного и множественного числа, а также падежные формы.

Дальнейшего семантического развития лексикализованной аббревиатуры не последовало, т.е. не был отмечен ее переход в лексическую систему другого языка с изменением значения.

ЛИТЕРАТУРА

1. Хлусова А.И. Аббревиация в компьютерном дискурсе: структурные и функциональные особенности аббревиатур URL: http://earchive.tpu.ru/ bitstream/11683/18468/1/conference_tpu-2015-C77-V1-061.pdf (дата обращения 08.07.2021)

2. Выклюк И.В. Лингвопрагматические особенности функционирования аббревиатур в турецком языке URL: https://seanewdim.com/ uploads/3/4/5/1/34511564/vykliuk_i._v._linguopragmatic_peculiarities_of_functioning_of_the_abbreviations_in_turkish_language.pdf (дата обращения 10.07.2021)

3. Вишнякова Е.А. Место аббревиации в словообразовательной системе современного английского языка // Научные ведомости БелГУ. Серия: Гуманитарные науки. 2014. №6 (177). URL: https://cyberleninka.ru/article/n/mesto-abbreviatsii-v-slovoobrazovatelnoy-sisteme-sovremennogo-angliyskogo-yazyka (дата обращения: 03.04.2020).

4. Сергеева Т.С. Аббревиатура в системе лексических сокращений URL: https://www.gramota.net/articles/issn_1997-2911_2013_6-2_47.pdf (дата 0браще- 
ния 14.07.2021)

5. Ракитина Н.Н. Аббревиатуры как языковые единицы URL: www.gramota.net/materials/1/2009/8-1/52.html (дата обращения 12.07.2021)

6. Максимова Т.В. Современные тенденции развития сокращения как способа словообразования в английском языке // Вестник ВолГУ. Серия 2: Языкознание. 2003. №3. URL: https://cyberleninka.ru/article/n/sovremennye-tendentsii-razvitiya-sokrascheniya-kak-sposoba-slovoobrazovaniya-v-angliyskom-yazyke (дата обращения: 14.07.2021).

7. Келлер, И.М. Языковой знак как номинативная единица / И.М. Келлер // Язык: Мультидисциплинарность научного знания : научный альманах / под ред. О.В. Труновой; Алтайская государственная педагогическая академия; Лингвистический институт. - Барнаул: Алтайская государственная педагогическая академия, 2010. - С. 86-93.

8. Князев Н.А. Лингвопрагматические свойства сокращений в современном английском языке URL: https://pgu.ru/upload/iblock/b3d/uch_2014_ii_05.pdf (дата обращения 10.07.2021)

9. Ярмашевич М.А. Структурные характеристики русских графо-лексических аббревиатур // Изд. Сарат. ун-та. Нов.сер. Сер. Филология. Журналистика. 2019. Т. 19, вып. 3. С. 261-267.

10. Сафонова Н.Н. Лексемы от аббревиатурного происхождения в современном русском языке // Аналитика культурологии. 2011. №21. URL: https:// cyberleninka.ru/article/n/leksemy-ot-abbreviaturnogo-proishozhdeniya-v-sovremennom-russkom-yazyke (дата обращения: 18.07.2021).

11. Ярмашевич М.А. аббревиация в современных европейских языках: структурный, семантический и функциональный аспекты: автореферат дис. ... доктора филологических наук, - Саратов, 2004. - 40 c.

12. Кербер, Е.В. Явление гибридизации второго и третьего порядка в английской терминологии компьютерных стандартов и микроэлектроники / Е.В. Кербер, И.А. Беликова, Ю.Е. Костерина // Современная наука: актуальные проблемы теории и практики. Серия: Гуманитарные науки. - 2020. - № 5-2. C. 80-85.

13. Усачев, В.А. Сокращения и аббревиация в английских текстах как одна из особенностей развития языка / В.А. Усачев // Восточнославянская филология. Языкознание. - 2016. - № 2(28). - С. 173-179.

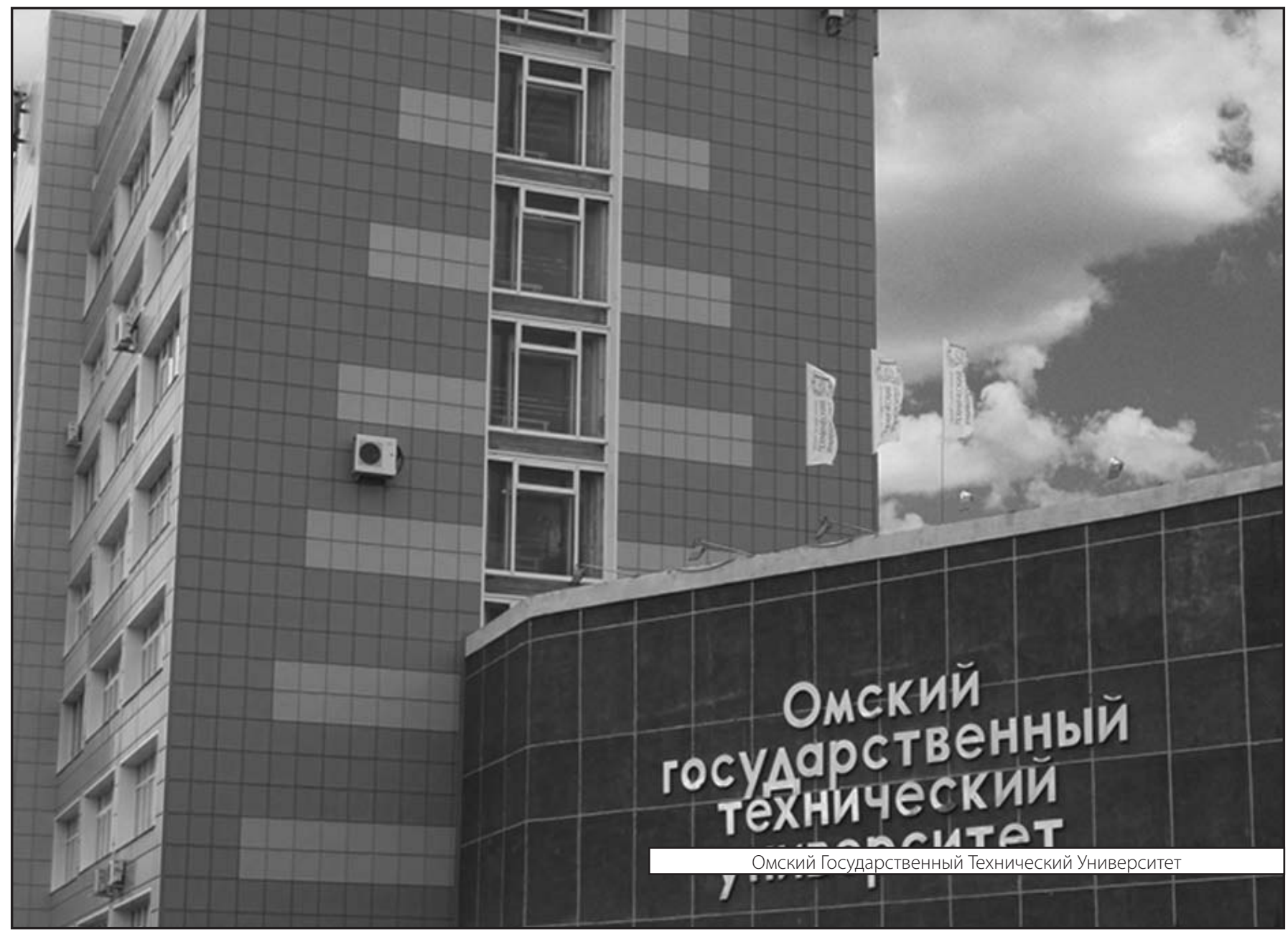

